\title{
Awareness and utilization of personal protective equipment among small-scale welders in Cross River State, Nigeria: a descriptive cross-sectional study
}

\author{
Esu EB ${ }^{1}$, Ekanem UE ${ }^{1}$ \\ ${ }^{1}$ Department of Public Health, University of Calabar, Calabar, Nigeria
}

Submitted: $30^{\text {th }}$ November 2020

Accepted: $18^{\text {th }}$ January 2021

Published: $30^{\text {th }}$ June 2021

\begin{abstract}
Objective: Rapid urbanization and industrialization in the many low- and middle-income countries means that there is a growing demand for the welding industry. Previous studies in Nigeria, and other low- and middle-income countries have reported a significant discrepancy between awareness and consistent and appropriate use of personal protective equipment (PPE). This study assessed the awareness and utilization of PPE among smallscale welders in Calabar South, Cross River State, Nigeria.

Methods: This study was conducted in Calabar South Local Government Area using a descriptive cross-sectional design. Data collection was with an interviewer-administered semi-structured questionnaire, and an observation checklist was used to monitor the use of PPE among small-scale welders.

Results: One hundred and sixteen small-scale welders were surveyed with a mean age of $34.9 \pm 9.1$ years. Almost $90 \%$ of respondents had completed at least primary education. Eighty-one respondents $(69.8 \%)$ were aware of PPE. Three-quarters of respondents $(61 / 81)$ knew PPE protected the user from injury. The most frequently identified type of welding PPE among the respondents aware of PPE, were safety goggles (38.3\%), hand gloves $(25.9 \%)$, safety boots $(19.8 \%)$, and coveralls $(9.9 \%) .83 .6 \%$ had access to PPE at work. However, only $14.4 \%$ reported using PPE consistently. Observation revealed that the PPE most frequently used, sunglasses, were not the recommended welding goggles.

Conclusion: The low utilization of PPE calls for stricter enforcement of occupational health and safety regulations among welders in the informal sector, including implementing PPE awareness programs.
\end{abstract}

Keywords: Awareness, Occupational health, Personal protection, Utilization, Welders

\section{Plain English summary}

This study conducted in Calabar South Local Government Area assessed awareness of and utilization of PPE among small-scale welders using a survey design and found that respondents in this study had good knowledge of and access to PPE. Despite having good knowledge and access, low utilization of PPE was reported among respondents in the workplace, which meant that awareness among welders in the study area did not translate into utilization. This points to the need for a system of better and stricter enforcement of work safety measures among welders and improved education on the need for consistent and proper utilization of PPE.

\section{Background}

Globally, the welding industry comprises skilled and semi-skilled workers, numbering over 5 million who contribute to several sectors of the economy such as manufacturing, real-estate construction, automotive repairs, and mining (1, 2).

According to the International Labour Organization, globally, there are 270 million occupational accidents and 160 million 
occupational diseases each year. These result in about 2 million deaths annually (3).

The welding occupation involves heating and fusing metals at high temperatures and is thus associated with tremendous physical and chemical hazards including heat, high noise levels, radiation, and fumes $(4,5,6,7)$. The nature of the occupational exposure from welding is dependent mainly on the welding type, materials being welded, and the consistent and appropriate use of personal protective equipment. The use of personal protective equipment such as eye goggles, boots, and overalls is known to mitigate the health hazards from occupational exposures (8).

Rapid urbanization and industrialization in many low- and middle-income countries means that there is a growing demand for the welding industry. Several studies carried out in Nigeria, and other LMICs have reported a significant discrepancy between awareness and PPE utilization $(9,10,11,12,13)$. A previous study from Calabar, Cross River State had observed welders seldom used protective goggles during welding (6). This study aimed to assess the awareness of and utilization of personal protective equipment among small-scale welders in Calabar South, Cross River State, Nigeria.

\section{Methodology}

This study was conducted in Calabar South Local Government Area, a semi-urban settlement in Cross River State. Calabar South LGA covers an area of $264 \mathrm{~km}^{2}$. Calabar South comprises 12 wards and has a projected population of about 278,260 in 2020 , assuming an annual growth rate of $2.6 \%$ from 2006 Nigeria Population and housing Census figures (14). Calabar South has one secondary facility, 27 primary health centers, and several private health facilities. The predominant ethnic groups are the Efiks, Efuts, Quas, and Ibibios. Most occupants are civil servants, traders, subsistence farmers, and fishermen (15). A descriptive cross-sectional design was adopted for this study. As no sampling frame existed, the research team generated a sampling frame of all the small-scale welders in Calabar South by snowball sampling. All one hundred sixteen small-scale welders identified were selected for inclusion in this study.

Data collection was with an intervieweradministered semi-structured questionnaire that elicited information on sociodemographic characteristics, knowledge of the importance of PPE use, utilization of PPE, barriers to PPE utilization, and welder's perception of their occupational hazards. An intervieweradministered questionnaire was used because some respondents were expected to be without formal education. Also, an observation checklist adapted from the Occupational Safety and Health Administration (OHSA) PPE compliance audit checklist (16) was used to monitor the use of PPE among small-scale welders. Data analysis was done using the Statistical Package for Social Science (SPSS) software (Version 20). Descriptive statistics have been used to summarize and present data. Verbal consent was obtained from all respondents, and participation was voluntary. All respondents were assured of confidentiality and anonymity of data collected.

\section{Results}

A total of 116 small-scale male welders participated in the study. The mean age of welders was $34.9 \pm 9.1$ years. Almost $90 \%$ of respondents had completed at least primary education. Slightly over half $(50.8 \%)$ of the welders had been in employment as welders for 6-10 years (See Table 1).

Table 1: Sociodemographic characteristics of respondents $(n=116)$ Calabar South, Nigeria, 2019

\begin{tabular}{lcc}
\hline Variables & Frequency & Percentage \\
Age (in years) & & \\
$18-25$ & 23 & 19.8 \\
$26-33$ & 27 & 23.4 \\
$34-41$ & 34 & 29.3 \\
$42-49$ & 29 & 25.0 \\
50 \&above & 3 & 2.5 \\
Total & 116 & 100 \\
Religion & & \\
Christianity & 112 & 96.5 \\
Traditional Religion & 1 & 0.9 \\
No religion & 3 & 2.6 \\
Total & 116 & 100
\end{tabular}




\begin{tabular}{lcc} 
Educational attainment & & \\
No formal & 12 & 10.3 \\
Primary & 28 & 24.1 \\
Secondary & 57 & 49.1 \\
Tertiary & 19 & 16.4 \\
Total & 116 & 100 \\
Marital Status & & \\
Single & 41 & 35.3 \\
Married & 68 & 58.6 \\
Divorced/Separated & 4 & 3.5 \\
Widowed & 3 & 2.6 \\
Total & 116 & 100 \\
Duration in employment & & \\
Less than a year & 12 & 10.3 \\
1-5 & 41 & 35.3 \\
6-10 & 59 & 50.8 \\
11 years + & 4 & 3.5 \\
Total & 116 & 100 \\
\hline
\end{tabular}

Awareness of Personal Protective Equipment (PPE)

Eighty-one respondents (69.8\%) were aware of PPE. Among welders who were aware of PPE, the primary sources of information were television $(48.2 \%)$ and radio $(33 \%)$.

Three-quarters of respondents (61/81) who were aware of PPE, stated they protected the user from injury. The most frequently identified type of welding PPE among the respondents were safety goggles $(38.3 \%)$, hand gloves $(25.9 \%)$, safety boots $(19.8 \%)$, and coveralls (9.9\%) as shown in Table 2. About $15 \%$ (12) did not think PPEs were necessary.

Table 2: Welders' awareness of PPE $(n=116)$ Calabar South, Nigeria, 2019

\begin{tabular}{lcc}
\hline Variables & Frequency & Percentage \\
\hline Awareness of PPE & & \\
Yes & 81 & 69.8 \\
No & 35 & 30.2 \\
Total & 116 & 100 \\
Source of information on PPE & 39 & \\
Television & 33 & 48.2 \\
Radio & 9 & 40.7 \\
Posters/Handbill & 81 & 11.1 \\
Total & 100 \\
Definition of PPE & 61 & \\
Protective clothing to protect the user from injury & 17 & 75.3 \\
Clothing that causes discomfort or heat & 21.0 \\
To protect the user from skin diseases & 1 & 1.2 \\
To protect the user from the splash of blood & 2 & 2.5 \\
Total & 81 & 100 \\
Is PPE necessary? & & \\
Yes & 69 & 85.2 \\
No & 12 & 14.8 \\
Total & 81 & 100 \\
Welding PPE identified by respondents & & \\
Safety goggles & 31 & 38.3 \\
Hand gloves & 21 & 25.9 \\
Safety boots & 16 & 19.8 \\
Coverall & 8 & 9.9 \\
Face mask & 4 & 4.9 \\
Respirator & 1 & 1.2 \\
Total & 81 & 100 \\
\hline
\end{tabular}




\section{Utilization of Personal Protective Equipment} (PPE)

The majority of the respondents, $97(83.6 \%)$, had PPE for use during work hours. The most frequently used PPE among the welders was safety goggles $76(65.5 \%)$, as shown in Table 3 . Seventy-nine $(68.1 \%)$ welders reported utilization of at least one PPE. For some welders, these were used along with hand gloves, coveralls. Consistent use of PPE was low, with only $14.4 \%(14 / 97)$ reporting that they used PPEs always. A considerable proportion of respondents, $63.9 \%$ reportedly used PPEs most of the time (Table 3). Only $7.7 \%(7 / 97)$ had received training on the use of PPE and safety in the workplace. The majority of the respondents $101(87.1 \%)$ were willing to be trained on the use of PPE and safety in the workplace.

Table 3: Welders' utilization of PPE $(n=116)$ Calabar South, Nigeria, 2019

\begin{tabular}{lcc}
\hline Variables & Frequency & Percentage \\
\hline Had access to PPE at work & & \\
Yes & 97 & 83.6 \\
No & 19 & 16.4 \\
Total & & 100 \\
*Utilization of PPE & 44 & 37.9 \\
Hand gloves & 41 & 35.3 \\
Coverall & 31 & 26.7 \\
Safety boots & 76 & 65.5 \\
Safety goggles & & \\
Frequency of PPE use & 14 & 14.4 \\
Always & 62 & 63.9 \\
Most times & 9 & 9.3 \\
Sometimes & 12 & 12.4 \\
Rarely & 97 & 100 \\
Total & & \\
Training on the use of PPE \& safety at the workplace & 9 & 7.7 \\
Yes & 107 & 92.3 \\
No & 116 & 100 \\
Total & & \\
Willing to be trained on the use of PPE & 101 & 87.1 \\
Yes & 15 & 12.9 \\
No & 116 & 100 \\
Total & & \\
\hline
\end{tabular}

${ }^{*}$ Multiple responses

The main reasons for the non-utilization of PPE were discomfort associated with use (41.4\%) and lack of funds to buy PPE $(39.6 \%)$. Of the remaining respondents, $19 \%$ (22) stated their PPEs were either worn out or damaged.

\section{Observation of PPE use among welders}

The observational checklist consisted of a list of PPEs that the researcher used to observe the utilization of PPE among welders. From Table 4 , the majority of the welders $64(55.2 \%)$ used sunshades instead of the recommended safety goggles, $39(33.6 \%)$ welders out of 116 used hand gloves, $22(19 \%)$ welders out of 116 used safety boots, $13(11.2 \%)$ welders out of 116 used coverall. In contrast, none of the welders used a face mask, respirator, or earmuffs. The observation revealed that the welders in Calabar south utilized PPE but incorrectly in some cases. This is due to the lack of training on PPE use and its importance.

Table 4: Observation of PPE use among welders $(n=116)$ Calabar South, Nigeria, 2019

\begin{tabular}{ccl}
\hline Types Of PPE & Utilization rate & \multicolumn{1}{c}{ Remarks } \\
\hline Hand Gloves & $39 / 116(33.6 \%)$ & $\begin{array}{l}\text { All the hand gloves used were the } \\
\text { recommended type. However, } 9(23.1 \%) \text { were } \\
\text { worn out. }\end{array}$ \\
Face Mask & $0 / 116$ & All the respondents had no face mask for use.
\end{tabular}




\begin{tabular}{|c|c|c|}
\hline Cover All & $13 / 116(11.2 \%)$ & $\begin{array}{l}\text { Only } 13 \text { welders used their coverall. Others } \\
\text { claimed to have. }\end{array}$ \\
\hline Respirators & $0 / 116$ & Ione of the respondents had a respirator. \\
\hline Safety B & $22 / 116(19 \%)$ & ropriate safety boots. \\
\hline Safety Goggles & $64 / 116(55.2 \%)$ & $\begin{array}{l}\text { All the } 64 \text { welders had sunshades which are } \\
\text { not the recommended type of safety goggles. }\end{array}$ \\
\hline arm & $0 / 116$ & he welders used earmuffs. \\
\hline
\end{tabular}

\section{Discussion}

This study aimed to assess the awareness and utilization of personal protective equipment among small-scale welders in Calabar, Cross River State, Nigeria. In this study, $54.3 \%$ of the respondents had more than five years' experience. Other studies in Nigeria (17) have shown $74.8 \%$ of welders with more than a decade of experience.

Welders surveyed in this study had good knowledge of PPE and safety goggles were the most frequently reported PPE used by them. This finding is similar to other studies $(2,11,12)$ conducted in Nigeria that found safety goggles to the most frequently used PPE. Safety goggles, hand gloves, and safety boots were the main PPE utilized by study respondents based on self-report or observation of welders. The consistent use of PPE was low among respondents despite $84 \%$ reporting they had access to PPE in the workplace. Awareness among welders in the study area did not translate into consistent use. This is similar to findings from similar studies that found low utilization of personal protective eye devices (18) and the utilization of at least one type of PPE (9). However, a study in Nepal (19) reported a utilization rate of at least one PPE to be $95.5 \%$ among welders in metal workshops much higher than the $68.1 \%$ observed in this study.

The findings of the study showed that the barriers to the use of PPE in the study area are discomfort and lack of funds to buy PPE. Lombardi and colleagues (20) found that among workers in the United States of America, inadequate financing and difficulties in obtaining them were barriers to the utilization of PPE.

Only about $8 \%$ of the respondents had received training on the use of PPE and safety at the workplace. A study from South India (21) found only about $19.1 \%$ of welders had received institutional training. This underscores the need for safety regulatory services to be extended to this occupational group.

Welding is associated with various physical and chemical hazards when welders do not continuously utilize appropriate PPE. The consistent use of recommended PPE to minimize these hazards should be a priority. Thirty percent of welders interviewed in this study were not aware of PPEs, and only $14.4 \%$ consistently used PPE during welding. From observation, the sunglasses being used by welders in the study area were not the recommended welding goggles, thus exposing their eyes to harmful ultraviolet radiation. This finding is similar to a study from Nepal (9) and another from Pakistan (20).

Most welders in the study area had never received training on the use of PPE and workplace safety. There is a significant knowdo gap between the knowledge of welders regarding awareness of PPE and the consistent use of PPE at work by the welders. Appropriate interventions need to be designed to address this gap, especially as most welders expressed willingness to be trained. Occupational Health and Safety need to be promoted by the Nigeria Labor Congress and the national welder's union.

Limitations of this study include the risk of social desirability bias and self-reports. However, to mitigate this risk, observation of PPE utilization was undertaken at the worksites of all welders sampled.

\section{Conclusion}

The low utilization of PPE calls for stricter enforcement of occupational health and safety regulations among welders in the informal sector, including implementing PPE awareness programs. This is particularly important as most respondents expressed their willingness to be trained on occupational health and safety.

The Federal Ministry of Labour and Employment in Nigeria should also enforce operating guidelines and a safe working environment for welders employed in the smallscale, informal sector. Interventions to improve welders' awareness and utilization of PPE should focus on providing safety training, enforcement of worksite safety regulations, and knowledge of occupational hazards. Also, further studies should investigate the use of other workplace safety measures such as the use of engineering and administrative controls, regulation, and enforcement.

\section{List of abbreviations \\ PPE: Personal Protective Equipment}




\section{Declarations}

Ethics approval and consent to participate Ethical approval to conduct this study was obtained from the Research Ethics Committee of Department of Public Health, University of Calabar, Calabar on 21 June 2019 and reference number UC/CMS/PUH/ETH/1940. Verbal consent was obtained from all participants before data collection.

\section{Consent for publication}

The authors hereby give consent for the publication of our work under the creative commons CC Attribution-Non-commercial 4.0 license.

\section{Availability of data and materials}

The data and materials associated with this research will be made available by the corresponding author upon reasonable request.

\section{Competing interests}

The authors have no competing interests.

\section{Funding}

This research did not receive any specific grant from funding agencies in the public, commercial, or not-for-profit sectors.

\section{Authors' contributions}

EEB and EUE-conceptualized and designed the study. EEB wrote the first draft of the manuscript. EUE-was responsible for data collection and EEB- supervised data collection. All authors read and approved the final manuscript.

\section{Acknowledgments}

The authors would like to acknowledge all the welders who participated in the study.

\section{References}

1. Bhumika TV, Thakur M, Jaswal R, Pundir P, Rajwar E. Occupational injuries and safety measures adopted by welding workers: a cross-sectional study in South India. Global Journal of Medicine and Public Health. 2014;3(5):1-6.

2. Tagurum YO, Gwomson MD, Yakubu PM, Igbita JA, Chingle MP, Chirdan OO. Awareness of occupational hazards and utilization of PPE amongst welders in Jos Metropolis, Nigeria. International Journal of Research in Medical Sciences. 2018 Jul;6(7):2227-33. https://doi.org/10.18203/23206012.ijrms20182808
3. International Labour Organization. ILO introductory report: Global trends and challenges on occupational safety and health. Geneva; 2011.

4. Antonini JM. Health effects associated with welding In: Bassim N, editor. Comprehensive Materials Processing. 2014; Chapter 8. 49-70. doi:10.1016/B9780-08-096532-1.00807-4

5. Joseph N, Venkatesh V, Akash SK, Hegde S, Moras E, Shenoy NP. Occupation Hazards-Pattern, awareness, and preventive measures among welders from an unorganized sector in India. Journal of Clinical and Diagnostic Research. 2017 May;11(5):

LC23. https://doi.org/10.7860/jcdr/2017/24977.98 $\underline{79}$

6. Davies KG, Asana U, Nku CO, Osim EE. Ocular effects of chronic exposure to welding light on Calabar welders. Nigerian Journal of Physiological Sciences. 2007;22(1-2).

https://doi.org/10.4314/nips.v22i1-2.54895

7. Erhabor GE, Fatusi S, Obembe OB. Pulmonary function in ARC-welders in lleIfe, Nigeria. East African medical journal. 2001;78(9):461-4.

https://doi.org/10.4314/eami.v78i9.8975

8. Onwukwe OS, Azubike NC, Udeani TK, Onyemelukwe AO, Chukwuagu CF, Achukwu PU. Changes in the Haematological Profile and Frequency of Nuclear Abnormalities in Exfoliated Buccal Cells of Automobile Welders in Enugu, Nigeria. Research Journal of Environmental Toxicology 2018;12:56-62. https://doi.org/10.3923/riet.2018.56.62

9. Budhathoki SS, Singh SB, Sagtani RA, Niraula SR, Pokharel PK. Awareness of occupational hazards and use of safety measures among welders: a crosssectional study from eastern Nepal. BMJ open 2014;4:e004646. https://doi.org/10.1136/bmjopen-2013004646

10. Isah EC, Okojie OH. Occupational health problems of welders in Benin City, Nigeria. Journal of Medicine and Biomedical Research. $2006 \quad$ Jun;5(1):64-9. https://doi.org/10.4314/jmbr.v5i1.10685

11. Sabitu K, lliyasu Z, Dauda MM. Awareness of occupational hazards and utilization of safety measures among welders in Kaduna metropolis, Northern Nigeria. Annals of African medicine. 2009 Jan 1;8(1):46. https://doi.org/10.4103/1596-3519.55764

12.Adewoye KR, Awoyemi AO, Ibirongbe DO, Babatunde OA, Ibrahim T. Knowledge on the health effects of welding smoke, use of 
PPE among electric-arc welders in llorin south, north-central Nigeria. Journal of Asian Scientific Research. 2013;3(9):92432.

13. Fiebai B, Awoyesuku EA. Ocular injuries among industrial welders in Port Harcourt, Nigeria. Clinical ophthalmology. 2011;5:1261. https://doi.org/10.2147/opth.s20297

14.National Population Commission. Population and housing census of the Federal Republic of Nigeria 2006.

15. Osuchukwu N, Osuchukwu E, Eko J, Samson-Akpan P, Akpasa A, Osonwa K, et al. Perception of the determinants of maternal mortality in Calabar South Local Government Area of Cross River State, Nigeria. International Journal of Public Health, Pharmacy and Pharmacology 2015;1(1):1-13.

https://doi.org/10.5296/isr.v4i2.3836

16. Grubbs JR, Nelson SM. Safety made easy: A checklist approach to OSHA compliance. Third Edition. Maryland, USA: Government Institutes; 2007.

17. Isah EC, Okojie OH. Occupational health problems of welders in Benin City, Nigeria. Journal of Medicine and Biomedical Research. $2006 \quad$ Jun;5(1):64-9. https://doi.org/10.4314/imbr.v5i1.10685

18. Eze BI, Okoye O, Aguwa EN. Awareness and utilization of welders' personal protective eye devices and associated factors: Findings and lessons from a Nigerian population. Workplace Health \& Safety. $\quad 2015 \quad$ Apr;63(4):170-8. https://doi.org/10.1177/216507991557866 $\underline{5}$

19. Ghimire A, Budhathoki SS, Niraula SR, Shrestha A, Pokharel PK. Work-related Injury among Welders Working in Metal Workshops of Dharan Municipality, Nepal. Journal of Nepal Health Research Council. 2018 Jul 5;16(2):156-9. https://doi.org/10.3126/jnhrc.v16i2.20302

20. Lombardi DA, Verma SK, Brennan MJ, Perry MJ. Factors influencing worker use of personal protective eyewear. Accid Anal Prev. 2009 Jul;41(4):755-62. https://doi.org/10.1016/i.aap.2009.03.017

21. Kumar SG, Dharanipriya A, Kar SS. Awareness of occupational injuries and utilization of safety measures among welders in coastal South India. Int J Occup Environ Med. 2013 Oct;4(4):172-7. https://doi.org/10.4103/0019-5278.146911

22. Hassan SM, Nasir U, Anwar K, Talib U. An assessment of the level of awareness and reported complaints regarding occupational health hazards and the utilization of personal protective equipment among the welders of Lahore, Pakistan. Int J Occup Environ Health. 2017 Apr;23(2):98-109. https://doi.org/10.1080/10773525.2018.14 26259 